\title{
Estratégias de ensino de ciências e a promoção do pensamento crítico em contexto brasileiro
}

Camila Boszko*, Roque Ismael da Costa Güllich**

\section{Resumo}

Internacionalmente, os estudos sobre o processo de ensino e aprendizagem baseado na promoção do pensamento crítico $(P C)$ vêm sendo cada vez mais valorizados, porém, não em contexto brasileiro. Acredita-se que analisar as estratégias de ensino utilizadas no Brasil para ensinar ciências é crucial, no sentido de criar subsídios para facilitar a compreensão acerca das possibilidades de promoção do PC, bem como de seus desdobramentos no desenvolvimento curricular e em processos de formação de professores. Foi realizada uma análise dos referenciais brasileiros que discutem a promoção do PC, o que mostrou a precariedade de discussão dessa forma de pensamento em contextos educativos. Para uma melhor compreensão, procedeu-se à análise das seguintes estratégias: experimentação investigativa, ensino por investigação, educar pela pesquisa, resolução de problemas, situações de estudo e pedagogia de projetos. Objetiva-se instigar novos estudos, que favoreçam professores na hora de escolher/adaptar a estratégia de ensino para sua realidade e estimulem um processo de escolha mais reflexivo e direcionado ao desenvolvimento de atitudes críticas. Acredita-se que estudos nesta direção possam ser empreendidos em análises de políticas públicas educacionais curriculares, materiais didáticos e processos de formação de professores, na perspectiva de envidar esforços para avançar no desenvolvimento desta área, em contexto brasileiro.

Palavras-chave: Desenvolvimento curricular. Didática. Educação. Ensino de ciências. Formação de professores.

* Licenciada em Ciências Biológicas pela Universidade Federal da Fronteira Sul (UFFS). Mestranda em Educação na Universidade de Passo Fundo (UPF). Bolsista Prosuc Capes/UPF. E-mail: camila.boszko@gmail.com

** Professor adjunto de Prática de Ensino e Estágio Supervisionado em Ciências e Biologia da UFFS. E-mail: roquegullich@uffs.edu.br

Recebido em: 28/09/2018 - Aceito em: 30/10/2018.

https://doi.org/10.5335/rbecm.v2i1.8697 


\section{Introdução}

Sabe-se que os conteúdos de ensino são marcados pela forma essencialmente disciplinar, fragmentada, descontextualizada e linear de organização (MALDANER; ZANON, 2004). A tradição na formação de professores, dentro da educação em ciências, é uma forte corrente/perspectiva de pesquisa e atuação, porém pouco tem produzido nos últimos anos em termos de propostas curriculares de formação e ensino de ciências no âmbito brasileiro.

O contexto da sociedade atual impõe a necessidade de haver cada vez mais cidadãos ativos e críticos, que sejam capazes de responder às exigências impostas. Logo, faz-se necessário que seja ofertada uma preparação para o exercício da cidadania, de maneira responsável e consciente. Para tanto, não basta mediar "apenas" conhecimentos. É preciso, também, estimular o desenvolvimento do pensamento crítico (PC) (GONÇALVES; VIEIRA, 2015).

O debate sobre o uso de estratégias de ensino que estimulem o desenvolvimento do PC nos estudantes vem sendo cada vez mais acentuado, com o objetivo de torná-los não só mais preparados profissional e socialmente, mas também para que consigam atender suas necessidades pessoais, oportunizando a estes que consigam visualizar e concretizar seus objetivos de vida.

Nos últimos anos, muitos documentos foram elaborados a partir de um processo de ensino e aprendizagem baseado no estímulo do PC e na construção da alfabetização científica. Muitos desses documentos têm como foco a reestruturação do currículo, dentre os quais, destacam-se como exemplos o projeto europeu "Beyond 2000: science education for the future" (MILLAR; OSBORNE, 1998 apud TENREIRO-VIEIRA; VIEIRA, 2013b) e o documento "Ciências físicas e naturais - competências essenciais no ensino básico", desenvolvido em Portugal, pelo Ministério da Educação/Departamento de Educação Básica, em 2001.

Porém, mesmo com essa crescente discussão em nível mundial e com a elaboração desses documentos norteadores desde 1990, no Brasil pouco se discute sobre o processo de PC e, ainda mais raramente, se desenvolve. Desde 1996, a Lei de Diretrizes e Bases da Educação Nacional (LDBEN) reforça a necessidade de uma reorganização na educação básica de forma urgente, para que seja possível acompanhar as mudanças sociais e culturais ocasionadas pelos processos de globalização. Entretanto, ainda hoje, o ensino de ciências se estrutura tendo como base a trans- 
missão de conceitos, o que ocasiona uma aprendizagem frágil, a qual nem sempre oportuniza ao aluno a compreensão de seu contexto histórico e social, muito menos lhe dá a possibilidade de intervir adequadamente no mundo.

O PC vem sendo discutido, em nível mundial, desde a década de 1980, com a perspectiva de um "[...] pensamento racional, reflexivo, focado naquilo em que se deve acreditar ou fazer" (ENNIS, 1985, p. 46). No Brasil, essa discussão ainda se encontra frágil, porém, cada vez mais ganha espaço para discussão em espaços de formação de professores, visto que possibilita encontrar respostas para as mudanças tecnológicas e as demandas de informações e conhecimentos globais (TENREIRO-VIERA, 2000). Dessa forma, o PC caracteriza-se como essencial na sociedade atual, moldada a partir de uma profunda transformação histórico-cultural (CHANCE, 1986), tendo em vista que possibilita ao aluno "[...] resolver os problemas com que se defronta, dar resposta às exigências do mundo atual e participar plenamente numa sociedade democrática" (TENREIRO-VIERA, 2000, p. 19). Outros professores e investigadores atribuem a importância do $\mathrm{PC}$ à sua própria natureza, como destaca Oliveira (1992, p. 9):

[...] muita da importância em educação do Pensamento Crítico advém da sua generalidade, pois tem tanto a ver com o conteúdo da educação, incluindo tudo o que os educadores procuram partilhar com os seus alunos, como com a forma, na qual se inserem os modos como os educadores tentam partilhar os conteúdos.

Em pesquisa realizada na Scientific Electronic Library Online (SicELO), foram encontrados quatro trabalhos relacionados à palavra-chave utilizada na busca "pensamento crítico". Desses, um é de autores portugueses (TENREIRO-VIEIRA; VIEIRA, 2013b); ou seja, há apenas três trabalhos que discutem a promoção do pensamento crítico em contexto brasileiro. São estes: “Contribuições dos objetos de aprendizagem para ensejar o desenvolvimento do pensamento crítico nos estudantes nas aulas de Física" (BULEGON; TAROUCO, 2015); "Pesquisa na escola: que espaço é esse? O do conteúdo ou o do pensamento crítico" (NININ, 2008); "Fóruns online na formação crítico-reflexiva de professores de línguas estrangeiras: uma representação do pensamento crítico em fases na/pela linguagem” (ROZENFELD, 2014). Já no banco de teses da Coordenação de Aperfeiçoamento de Pessoal de Nível Pessoal (Capes), foi encontrado apenas um trabalho que discute a formação de professores de ciências e que tem como discussão estratégias de PC e/ou a discussão do pro- 
cesso de formação de professores: "O ensino de ciências nos anos iniciais do ensino fundamental: ressignificando a formação de professores” (BONELLI, 2014, p. 13).

No banco de teses e dissertações do Instituto Brasileiro de Informação em Ciência e Tecnologia (IBICT), foram encontrados 57 trabalhos, usando a palavra-chave "pensamento crítico", porém, somente um trabalho discute o PC numa perspectiva educativa, sendo este uma aproximação por conta do referencial da reflexão crítica e formação do profissional professor reflexivo: "Ensino da história e o pensamento reflexivo-crítico da professora no $3^{\circ}$ ano do ensino fundamental" (MEDEIROS, 2008). Ou seja, a revisão sinaliza que os programas relacionados à formação e ao ensino de ciências pouco têm discutido a temática de estratégias de desenvolvimento/promoção de PC na formação de professores de ciências e tampouco discutem estratégias de ensino de ciências com tal finalidade, o que reforça a ideia de pesquisar e aprofundar a temática em questão. Outro aspecto possível de ser depreendido da revisão é que o estado da arte desse conhecimento no Brasil é inicial e, portanto, precisa da atenção de pesquisas nessa temática.

A definição de PC pode apresentar divergências, mas se baseia, essencialmente, em um pensamento racional, que pode ser intencional e/ou focado, tendo como foco uma prática reflexiva e de constante avaliação. Paul (2005 apud TENREIRO-VIEIRA; VIEIRA, 2014, não paginado) caracteriza-o como:

[...] um pensamento disciplinado e autodirigido, em que o pensador crítico sistemática e intencionalmente: desenvolve atitudes; toma consciência dos elementos do pensamento; impõe critérios intelectuais ao pensamento; guia a construção do pensamento de acordo com critérios intelectuais e avalia a eficácia do processo de pensamento tendo em conta o propósito e os critérios intelectuais.

Tenreiro-Vieira e Vieira (2014, p. 15) apontam algumas capacidades relacionadas ao PC: "Fazer e responder a questões de clarificação, resumir, analisar argumentos, avaliar a credibilidade de fontes, fazer deduções, formular hipóteses e conclusões, fazer juízos de valor, identificar falácias, identificar assunções e argumentar”.

Ennis (1985 apud TENREIRO-VIEIRA; VIEIRA, 2014) aponta que o PC é geralmente utilizado para se referir às atividades prática e reflexiva, cuja meta é uma crença ou uma ação sensata. O PC envolve um conjunto de disposições, as quais vêm a traduzir o que o autor designa como sendo uma tendência para agir de forma crítica. Elas incluem: “[...] procurar estar bem informado, utilizar e mencionar 
fontes credíveis, procurar razões, procurar alternativas, ter abertura de espírito e procurar tanta precisão quanta o assunto o permitir" (ENNIS, 1985 apud VIEIRA, 2014, p. 176).

Os trabalhos mencionados apontam o fato de que existem poucos estudos focados no estabelecimento de estratégias promotoras do PC no ensino de ciências. Para Vieira (2014), devem ser dadas oportunidades aos alunos, em aulas de ciências, de experiências que promovam o PC e que possam desencadear a necessidade de construir e desenvolver conhecimentos, atitudes, valores, habilidades de pensamento e padrões, para que ocorra a aprendizagem em ciências e para que esta resulte no desenvolvimento da capacidade de saber agir responsavelmente em contextos e situações de relevância pessoal e social. Isso demonstra a forte inclinação da perspectiva do $\mathrm{PC}$, no ensino de ciências, para um ensino que leve à tomada de decisões e à análise do compromisso social destas.

Com base nas condições apresentadas na perspectiva do PC, nota-se uma real associação com o movimento de CTS e, em âmbito maior, com o movimento da alfabetização científica por esta via. Percebe-se, de acordo com as premissas discutidas, que o PC prevê a promoção de novas perspectivas de aprendizagem para os alunos, possibilitando-lhes aprender de forma racional e não passiva. Esta via racional permitirá o desenvolvimento de um olhar mais crítico e atento para o conhecimento como um todo, seja ele formal ou não, de forma que ele poderá analisar e decidir qual caminho seguir em determinada situação. Porém, para tanto, é necessário que os professores tenham uma preparação e que percebam a importância do desenvolvimento das capacidades do PC, bem como consigam identificar estratégias de ensino que permitam que estas sejam promovidas dentro dos objetivos propostos na temática a ser ensinada.

Além disso, o processo de ensino e aprendizagem deveria ser repensado desde a construção do currículo base, uma vez que estudos demonstram que mudar a prática educativa é quase ineficaz quando os diferentes componentes curriculares não buscam um objetivo comum, uma meta sincrônica (COSTA, 1985). Esta, também, pode ser uma das críticas às reformas brasileiras de ensino que, na maioria das vezes, não tem alinhamento entre propostas de ensino, de formação de novos professores e, tampouco, de produção dos materiais didáticos, gerando pouca ou nenhuma resolutividade em termos de mudanças estruturais, curriculares e de qualidade no ensino. 
Beyer (1984), em estudo desenvolvido nos Estados Unidos da América, identifica cinco grandes obstáculos para a promoção do PC nas escolas: a) os professores não concordam quanto a quais capacidades deveriam ser ensinadas; b) muitos professores não definem as capacidades de pensamento que desejam ensinar a partir de determinado conteúdo e/ou estratégia de ensino; c) os professores dificilmente fazem a seleção de instrumentos norteadores de determinadas capacidades; d) os currículos escolares são muito amplos, apresentando demasiadas capacidades para serem desenvolvidas em cada nível de ensino; e) os testes utilizados por muitas escolas não estimulam o desenvolvimento de capacidades de $\mathrm{PC}$, muitas vezes não possibilitando que se faça uma avaliação real da evolução das habilidades e competências desenvolvidas pelos alunos.

Ennis (1985) aponta que o PC é geralmente utilizado para se referir a atividades práticas e reflexivas, cuja meta é uma crença ou uma ação sensata. Para o autor, “[...] o pensamento crítico é uma forma de pensamento racional, reflexivo, focado no decidir em que acreditar ou o que fazer" (1985, p. 46). O PC envolve um conjunto de disposições, as quais traduzem o que o autor designa como sendo uma tendência para agir de forma crítica.

Tendo como base as ideias expostas, acredita-se que analisar estratégias de ensino utilizadas no Brasil para ensinar ciências é importante para facilitar a compreensão acerca das possibilidades de promoção do PC, bem como do desenvolvimento curricular e de processos de formação de professores que podem articular essas estratégias no seu bojo. Assim sendo, novos estudos podem favorecer professores na hora de escolher/adaptar a estratégia de ensino a ser utilizada de acordo com o objetivo a ser atendido, bem como podem estimular um processo de escolha mais reflexivo e direcionado ao desenvolvimento de atitudes críticas. Desse modo, tendo presentes os pressupostos apresentados, a pergunta de pesquisa se constitui da seguinte forma: as estratégias de ensino de ciências em contexto brasileiro favorecem a promoção do PC?

\section{Metodologia}

A presente pesquisa baseia-se em um processo de pesquisa qualitativa em educação, de caráter documental (LÜDKE; ANDRÉ, 2011). Inicialmente, realiza-se uma revisão da literatura e da constituição do estado da arte acerca da temática: PC 
na formação de professores e no ensino de ciências. Para tanto, foi realizada uma revisão na base de dados Scientific Electronic Library Online (SciELO), ${ }^{1}$ no banco de teses e dissertações da Capes $^{2}$ e no banco de teses e dissertações do IBICT, ${ }^{3}$ tendo como palavra-chave "pensamento crítico".

Após a revisão, partiu-se para a coleta e a seleção de textos sobre metodologias de ensino utilizadas amplamente para ensinar ciências no Brasil. Posteriormente, os dados foram gerados, tabulados, analisados e recordados, para possibilitar a sua sistematização ao longo da investigação. Sendo assim, foi necessária uma análise minuciosa, visto que havia um grande volume de dados a serem coletados e revisados. Para o aprofundamento teórico, a análise e o comparativo, foi utilizada a análise de conteúdo em três etapas: pré-análise, exploração do material e tratamento e interpretação dos resultados (LÜDKE; ANDRÉ, 2011). Foi demarcada a seleção de trechos/excertos dos trabalhos analisados para assinalar elementos constituintes do PC nas estratégias e contextualizá-las em relação às compreensões.

O principal referencial teórico compreende os critérios e os elementos que definem a promoção do PC em ciências, segundo Tenreiro-Vieira e Vieira (2013b), a saber: 1) conteúdo - a) termos/vocabulário, b) condições necessárias e suficientes, c) correlação e causa, d) hipóteses, e) conhecimento conceitual e axiológico; 2) capacidades de pensamento - a) tomar decisões, b) formular a questão/problema a resolver, c) estabelecer razões apropriadas, d) avaliar razões, e) analisar e avaliar argumentos, f) argumentar e contra-argumentar, g) procurar diferentes pontos de vista, h) identificar falácias, i) avaliar a credibilidade de uma fonte, j) fazer generalizações, k) formular hipóteses, l) tirar conclusões, m) investigar, incluindo o planejamento do controle efetivo das variáveis, n) fazer juízos de valor, o) avaliar crenças e cursos de ação, p) avaliar o processo de pensamento; 3) atitudes e valores - a) autoconfiança no uso das capacidades para pensar de forma crítica, b) atitude inquiridora, c) abertura de espírito, d) procurar estar bem informado, e) procurar tanta precisão quanto o assunto permitir, f) confiança e respeito pelas razões, g) humildade intelectual, h) coragem intelectual, i) empatia intelectual, j) integridade intelectual, k) perseverança intelectual, l) imparcialidade ou equidade; 4) normas e critérios - a) rigor, b) precisão, c) clareza, d) consistência, e) validade, f) controle de variáveis.

Para seleção de estratégias de ensino, foram pesquisadas referências teóricas brasileiras, levando em consideração o contexto histórico, social e cultural, bem 
como a ampla utilização no ensino de ciências. Para delimitar a área de procura e parametrizar o processo de análise, optou-se por desenvolver esta pesquisa, preferencialmente, com referências publicadas em forma de livros ou capítulos de livros. Realizou-se uma seleção de referências para seis estratégias de ensino utilizadas em contexto brasileiro, sendo elas: educar pela pesquisa; experimentação investigativa; resolução de problemas; ensino por investigação; situações de estudo; e pedagogia de projetos (Quadro 1).

Quadro 1 - Referências analisadas para as estratégias de ensino em contexto brasileiro

\begin{tabular}{|c|c|}
\hline $\begin{array}{l}\text { Estratégia de } \\
\text { ensino }\end{array}$ & Referências utilizadas \\
\hline $\begin{array}{l}\text { Educar pela } \\
\text { pesquisa }\end{array}$ & $\begin{array}{l}\text { MORAES, R.; GALIAZZI, M. C.; RAMOS, M. G. Pesquisa em sala de aula: fundamentos } \\
\text { e pressupostos. In: MORAES, R.; LIMA, V. M. R. (org.). Pesquisa em sala de aula: ten- } \\
\text { dências para a educação em novos tempos. Porto Alegre: EDIPUCRS, 2004. p. 9-24. }\end{array}$ \\
\hline $\begin{array}{l}\text { Experimentação } \\
\text { investigativa }\end{array}$ & $\begin{array}{l}\text { MOTTA, C. S.; DORNELES, A. M.; HECKLER, V.; GALIAZZI, M. C. Experimentação } \\
\text { investigativa: indagação dialógica do objeto aperfeiçoável. In: ENCONTRO NACIONAL } \\
\text { DE PESQUISA EM EDUCAÇÃO EM CIÊNCIAS, 9. Atas... Águas de Lindóia, SP: UFRJ, } \\
\text { 2013. p. 1-8. }\end{array}$ \\
\hline $\begin{array}{l}\text { Resolução de } \\
\text { problemas }\end{array}$ & $\begin{array}{l}\text { CAMPOS, M. C. C.; NIGRO, R. G. Didática das ciências: o ensino-aprendizagem como } \\
\text { investigação. São Paulo: FTD, } 1999 .\end{array}$ \\
\hline $\begin{array}{l}\text { Ensino por } \\
\text { investigação }\end{array}$ & $\begin{array}{l}\text { CAMPOS, M. C. C.; NIGRO, R. G. Didática das ciências: o ensino-aprendizagem como } \\
\text { investigação. São Paulo: FTD, } 1999 .\end{array}$ \\
\hline $\begin{array}{l}\text { Situações de } \\
\text { estudo }\end{array}$ & $\begin{array}{l}\text { MALDANER, O. A.; ZANON, L. B. Situação de estudo: uma organização do ensino. In: } \\
\text { MORAES, R.; MANCUSO, R. Educação em ciências: produção de currículos e forma- } \\
\text { ção de professores. ljuí: Editora Unijuí, 2004. p. 43-64. }\end{array}$ \\
\hline $\begin{array}{l}\text { Pedagogia de } \\
\text { projetos }\end{array}$ & $\begin{array}{l}\text { NOGUEIRA, N. R. Pedagogia dos projetos: uma jornada interdisciplinar rumo ao desen- } \\
\text { volvimento das múltiplas inteligências. São Paulo: Érica, } 2003 .\end{array}$ \\
\hline
\end{tabular}

Fonte: elaborado pelos autores.

\section{Analisando as estratégias de ensino}

O termo "estratégia" possui inúmeras definições, e muitas delas são confusas e contraditórias. Porém, neste trabalho, utiliza-se o termo como sendo detentor de um sentido: de sequências de processos/ações/atividades em prol de um objetivo central (CLARKE; BIDDLE, 1993). Bordenave e Pereira (2002) frisam a importância de que o professor venha a refletir sobre as estratégias de ensino, a fim de que o aluno possa ter diversas formas de interação, podendo vir a construir o conhecimento de acordo com suas experiências individuais, de forma a interpretar informações, experiências subjetivas, entre outros aspectos do ensino. Com o intuito de facilitar 


\section{a discussão e o entendimento da análise, foi elaborada uma caracterização das estratégias de ensino (Quadro 2).}

Quadro 2 - Caracterização das estratégias de ensino analisadas

\begin{tabular}{|c|c|}
\hline $\begin{array}{c}\text { Estratégias de } \\
\text { ensino }\end{array}$ & Características/descrição \\
\hline $\begin{array}{l}\text { Educar pela } \\
\text { pesquisa }\end{array}$ & $\begin{array}{l}\text { A pesquisa em sala de aula, como estratégia de ensino, constitui-se como um movimento } \\
\text { dialético, em espiral, que se inicia com o questionar dos estados do ser, fazer e co-- } \\
\text { nhecer, possibilitando construir novos argumentos, que possibilitem atingir novos } \\
\text { patamares deste ser, fazer e conhecer, estágios estes então comunicados a posteriori } \\
\text { (MORAES; GALIAZZI; RAMOS, 2004). }\end{array}$ \\
\hline $\begin{array}{l}\text { Experimentação } \\
\text { investigativa }\end{array}$ & $\begin{array}{l}\text { Esta estratégia propõe que se trabalhe a partir de perguntas dos alunos e do professor } \\
\text { sobre os fenômenos da natureza em estudo. A mediação ocorre por diferentes artefatos, } \\
\text { podendo ser: a fala, o diálogo, o registro escrito, entre outros. Exige a interação a partir } \\
\text { dos significados e sentidos iniciais atribuídos ao fenômeno estudado, para, na indagação, } \\
\text { buscar compreensões mais complexas sobre ele. A construção de hipóteses sobre } \\
\text { o que é observado no desenvolvimento do experimento favorece o surgimento de uma } \\
\text { rede de conexões entre o conhecimento dos estudantes e a teoria (MOTTA; DORNELES; } \\
\text { HECKLER; GALIAZZI, 2013). }\end{array}$ \\
\hline $\begin{array}{l}\text { Resolução de } \\
\text { problemas }\end{array}$ & $\begin{array}{l}\text { A situação problema é apresentada aos alunos a partir da leitura do enunciado do pro- } \\
\text { blema, da identificação e do debate das questões propostas, do esclarecimento de } \\
\text { termos desconhecidos e demais dúvidas. Depois, estimulam-se os alunos para busca- } \\
\text { rem identificar questões específicas contidas no problema, nesta etapa os alunos de- } \\
\text { vem propor hipóteses explicativas. Dando continuidade, são realizados estudos para } \\
\text { testar as hipóteses propostas e construir novos conhecimentos que permitam alcançar } \\
\text { os objetivos de aprendizagem. Feito isso, o problema e as possíveis soluções são (re) } \\
\text { discutidos em sala de aula, no grande grupo. Com a participação de todos os alunos, faz- } \\
\text {-se uma análise das hipóteses construídas, refutando-se as necessárias com base nos } \\
\text { conhecimentos construídos (CAMPOS; NIGRO, 1999). }\end{array}$ \\
\hline $\begin{array}{l}\text { Ensino por } \\
\text { investigação }\end{array}$ & $\begin{array}{l}\text { Inicia-se com a elaboração de um enunciado de algum problema norteador do con- } \\
\text { teúdo; a partir deste, os alunos constroem fundamentação e hipóteses, as quais serão } \\
\text { testadas por eles. Para tanto, elaboram-se estratégias de teste (experimental ou não) e a } \\
\text { posterior interpretação dos resultados. Pode-se fazer o compartilhamento dos resultados } \\
\text { entre os colegas (divulgação). Podem surgir novos problemas, e, então, reinicia-se o } \\
\text { ciclo (PÉREZ, } 1993 \text { apud CAMPOS; NIGRO, 1999). }\end{array}$ \\
\hline $\begin{array}{l}\text { Situações de } \\
\text { estudo }\end{array}$ & $\begin{array}{l}\text { Tem como objetivo desenvolver-se a partir da vivência social dos alunos, para que assim } \\
\text { possa vir a facilitar a interação pedagógica, de modo a estimular a construção (de for- } \\
\text { ma interdisciplinar) do pensamento e da aprendizagem. Procura integrar a vivência } \\
\text { do aluno com os conteúdos a serem ensinados. As situações de estudo são acompanha- } \\
\text { das e avaliadas na forma de pesquisa (MALDANER; ZANON, 2004). }\end{array}$ \\
\hline $\begin{array}{l}\text { Pedagogia de } \\
\text { projetos }\end{array}$ & $\begin{array}{l}\text { Caracteriza-se como uma mudança de postura pedagógica, fundamentada na concepção } \\
\text { de que a aprendizagem ocorre a partir da resolução de situações didáticas significa- } \\
\text { tivas para o aluno, de forma a aproximá-lo o máximo possível do seu contexto social, } \\
\text { por intermédio do desenvolvimento do senso crítico, da pesquisa e da resolução de } \\
\text { problemas (NOGUEIRA, 2003). }\end{array}$ \\
\hline
\end{tabular}

Fonte: elaborado pelos autores. 
Apesar de a discussão sobre o PC estar crescendo em âmbito internacional, as estratégias de ensino nem sempre levam em consideração as suas capacidades. As estratégias pesquisadas neste trabalho, a partir dos referenciais analisados, pouco contemplam, especificamente, o estímulo ao desenvolvimento do PC.

Goodlad (1983) realizou estudos sobre diferentes estratégias de ensino desenvolvidas no mundo e percebeu que as metodologias então utilizadas eram muito similares àquelas utilizadas no final do século XX. Não há a intenção de menosprezar as estratégias de ensino utilizadas pelos professores, o objetivo é discutir sobre as diferentes estratégias e sobre as diferentes capacidades que estas possibilitam desenvolver e/ou construir nos alunos, quando utilizadas para ensinar, especialmente ciências.

O desenvolvimento do PC, estimulado principalmente pelos professores e pela escola, constitui-se fator essencial para viver na sociedade atual. Por isso, este trabalho realiza uma análise das diferentes estratégias de ensino utilizadas no contexto da educação brasileira, buscando investigar se estas estimulam ou não a promoção do PC em ciências, bem como quais são os elementos constituintes instigados para a promoção deste. Com o objetivo de facilitar a compreensão da análise realizada, foi elaborado um quadro com as estratégias de ensino e os critérios analisados (Quadro 3). 


\section{Quadro 3 - Critérios analisados nas estratégias de ensino}

\begin{tabular}{|c|c|c|c|c|c|c|c|}
\hline & Elementos de análise & \multicolumn{6}{|c|}{ Estratégia de ensino } \\
\hline Critérios & Elementos constituintes & 1 & 2 & 3 & 4 & 5 & 6 \\
\hline \multirow{5}{*}{ 1. Conteúdo } & a) Termos/vocabulário & $\mathrm{X}$ & $x$ & $x$ & $x$ & $x$ & $x$ \\
\hline & b) Condições necessárias e suficientes & $\mathrm{X}$ & $\mathrm{x}$ & $x$ & $x$ & $x$ & $x$ \\
\hline & c) Correlação e causa & $\mathrm{X}$ & $x$ & $x$ & $x$ & $x$ & $x$ \\
\hline & d) Hipótese & $x$ & $x$ & $x$ & $x$ & & $x$ \\
\hline & e) Conhecimento conceitual e axiológico & & $\mathrm{x}$ & & $x$ & $x$ & $x$ \\
\hline \multirow{16}{*}{$\begin{array}{l}\text { 2. Capacidades de } \\
\text { pensamento }\end{array}$} & a) Tomar decisões & & $\mathrm{x}$ & $x$ & & & $x$ \\
\hline & b) Formular a questão/problema a resolver & $\mathrm{X}$ & $\mathrm{X}$ & $\mathrm{X}$ & $\mathrm{x}$ & $\mathrm{x}$ & $\mathrm{x}$ \\
\hline & c) Estabelecer razões apropriadas & & & $x$ & & & $x$ \\
\hline & d) Avaliar razões & & & $\mathrm{X}$ & & & $\mathrm{x}$ \\
\hline & e) Analisar e avaliar argumentos & $\mathrm{X}$ & $x$ & $x$ & $x$ & & $x$ \\
\hline & f) Argumentar e contra-argumentar & $\mathrm{X}$ & & $\mathrm{X}$ & $\mathrm{x}$ & $\mathrm{x}$ & $\mathrm{x}$ \\
\hline & g) Procurar diferentes pontos de vista & $\mathrm{X}$ & & & $x$ & $x$ & $x$ \\
\hline & h) Identificar falácias & $\mathrm{X}$ & $x$ & $x$ & $x$ & & $x$ \\
\hline & i) Avaliar a credibilidade de uma fonte & $\mathrm{X}$ & & & $x$ & & $x$ \\
\hline & j) Fazer generalizações & & $x$ & $x$ & $x$ & & $x$ \\
\hline & k) Formular hipóteses & $x$ & $x$ & $x$ & $x$ & & $x$ \\
\hline & I) Tirar conclusões & $\mathrm{X}$ & $x$ & $x$ & $x$ & $x$ & $x$ \\
\hline & $\begin{array}{l}\text { m) Investigar, incluindo o planejamento do controle efetivo de } \\
\text { variáveis }\end{array}$ & $\mathrm{x}$ & $\mathrm{x}$ & & $x$ & & $x$ \\
\hline & n) Fazer juízos de valor & & & & $x$ & & $x$ \\
\hline & o) Avaliar crenças e cursos de ação & $\mathrm{X}$ & & & $\mathrm{x}$ & & $\mathrm{x}$ \\
\hline & p) Avaliar o processo de pensamento & $\mathrm{X}$ & & & $x$ & & $x$ \\
\hline \multirow{12}{*}{ 3. Atitudes e valores } & $\begin{array}{l}\text { a) Autoconfiança no uso das capacidades para pensar de forma } \\
\text { crítica }\end{array}$ & $\mathrm{X}$ & $x$ & & $x$ & & $x$ \\
\hline & b) Atitude inquiridora & $\mathrm{X}$ & $x$ & & $x$ & & $x$ \\
\hline & c) Abertura de espírito & $\mathrm{X}$ & $x$ & & $x$ & & $x$ \\
\hline & d) Procurar estar bem informado & $\mathrm{X}$ & & $\mathrm{X}$ & $\mathrm{x}$ & & $\mathrm{x}$ \\
\hline & e) Procurar tanta precisão quanto 0 assunto permitir & $\mathrm{X}$ & & & $x$ & & $x$ \\
\hline & f) Confiança e respeito pelas razões & $\mathrm{X}$ & & & $x$ & & $x$ \\
\hline & g) Humildade intelectual & $\mathrm{X}$ & $x$ & $\mathrm{X}$ & $x$ & & $x$ \\
\hline & h) Coragem intelectual & $\mathrm{X}$ & $x$ & $x$ & $x$ & $x$ & $x$ \\
\hline & i) Empatia intelectual & $\mathrm{X}$ & & & $x$ & & $x$ \\
\hline & j) Integridade intelectual & & & & $x$ & & \\
\hline & k) Perseverança intelectual & $\mathrm{X}$ & $x$ & & $x$ & & $x$ \\
\hline & I) Imparcialidade ou equidade & & $x$ & $x$ & & & $x$ \\
\hline \multirow{6}{*}{ 4. Normas e critérios } & a) Rigor & $\mathrm{X}$ & $x$ & & $x$ & & \\
\hline & b) Precisão & & $x$ & & $x$ & & $x$ \\
\hline & c) Clareza & $\mathrm{x}$ & $\mathrm{x}$ & $\mathrm{x}$ & $\mathrm{x}$ & $\mathrm{x}$ & $\mathrm{x}$ \\
\hline & d) Consistência & $\mathrm{X}$ & $x$ & & $x$ & & $x$ \\
\hline & e) Validade & $X$ & $x$ & & $x$ & & $x$ \\
\hline & f) Controle de variáveis & & $\mathrm{X}$ & & & & $\mathrm{x}$ \\
\hline
\end{tabular}

Fonte: dados da pesquisa, 2018.

Legenda: estratégias de ensino: 1) educar pela pesquisa; 2) experimentação investigativa; 3) resolução de problemas; 4) ensino por investigação; 5) situações de estudo; 6) pedagogia de projetos. 
A partir dos dados analisados, pôde-se perceber que todas as estratégias utilizadas na investigação possuem alguns elementos constituintes promotores do PC, porém nenhuma possui todos os elementos analisados. A estratégia que mais se aproxima é a pedagogia de projetos, que apresenta 38 de 39 elementos constituintes do PC.

Ao analisar o critério conteúdo, percebeu-se que as seis estratégias de ensino analisadas possuem os quatro primeiros elementos constituintes. As estratégias variam somente quanto à presença do quinto elemento deste critério, o item "1-d", que somente a estratégia "situações de estudo" não contemplou. No referencial da estratégia "pedagogia de projetos", é possível identificar a presença deste elemento a partir do seguinte excerto: "[...] os alunos realizam a descrição de suas hipóteses planejadas, executam os processos para pesquisa e descobertas, analisam e refletem sobre suas aquisições e ainda utilizam-se de seu senso crítico, depurando e replanejando seus trabalhos" (NOGUEIRA, 2003, p. 128, grifo nosso).

Quanto ao elemento constituinte "1-e", que diz respeito ao conhecimento conceitual e axiológico, três das seis estratégias promovem. Uma das estratégias que apresentou este elemento foi "pedagogia de projetos", uma vez que esta estratégia pressupõe um objetivo que visa dar sentido às várias atividades, estimulando o aluno a desenvolver responsabilidade e autonomia (NOGUEIRA, 2003). Outra estratégia que apresentou este elemento foi a "experimentação investigava", como se pode perceber a partir do seguinte excerto:

Se reconhece como uma das potências da experimentação investigativa a sua capacidade de transformar os sujeitos envolvidos, modificando, reconstruindo e construindo representações sobre a realidade em que se encontram situados os sujeitos que a desenvolvem ao investigar um fenômeno, estando o diálogo, a escrita e o operar sobre a realidade, permeando este espaço (MOTTA; DORNELES; HECKLER; GALIAZZI, 2013, p. 5, grifo nosso).

Acredita-se que, quanto ao critério conteúdo, não foi possível uma análise plenamente satisfatória para avaliar a potencialidade de promoção do PC das estratégias de ensino do contexto brasileiro, pois foi analisado apenas um texto de referência acerca de cada metodologia/estratégia de ensino (conforme Quadro 1). Uma alternativa seria pensar em exemplos de estratégias de ensino ligadas às temáticas, para tentar contemplar de forma mais ampla a relação com os conteúdos de ensino, pois, nas escolhas de textos, prevalece a descrição teórico-metodológica das propostas. 
Quanto à análise das capacidades de pensamento, acredita-se que este seja o critério mais prudente para a análise da promoção do PC. Além disso, pôde-se perceber que o questionamento (formular a questão) caracteriza-se como fundamental nesta descrição e análise; na leitura dos referenciais bases da análise, em todos os casos, fica clara uma preocupação em estimular o questionamento no processo de ensino e aprendizagem. Segue como exemplo deste critério o seguinte excerto:

[...] a organização da experimentação investigativa na escola envolve trabalhar a partir de perguntas dos alunos e professor sobre os fenômenos da natureza em estudo. Essas perguntas oportunizam a construção de objetos aperfeiçoáveis, que trazem neles modelos de funcionamento desses objetos, o que possibilita questionamentos e argumentos que podem levar a melhor compreender o fenômeno e, com isso, aperfeiçoar este objeto produzido (MOTTA; DORNELES; HECKLER; GALIAZZI, 2013, p. 2, grifos nossos).

Os fatos expostos corroboram a afirmação de Vieira e Tenreiro-Vieira (2005) de que os questionamentos constituem a maior parte da investigação em sala de aula, bem como a afirmação de Moraes, Galiazzi e Ramos (2004) de que é a partir do questionamento que o indivíduo se assume como sujeito da realidade em que vive.

Um elemento presente nas cinco estratégias analisadas deste critério foi o "2-1" que é "tirar conclusões", talvez, porque, a partir do estímulo do questionamento, proposto no item "1-b", presente igualmente em todas as estratégias, venha como consequência o estímulo a criar/buscar conclusões pertinentes. Todos os outros itens foram observados em cinco estratégias, sendo estes os itens "2-e", "2-f", "2-h" e "2-k". A categorização do item "2-h" se justifica, por exemplo, a partir da afirmação de Campos e Nigro (1999), de que o ensino por investigação possibilita, a partir de atividades desenvolvidas por alunos e professores, verificar a veracidade das hipóteses explicativas, ou seja, perceber falácias. Os itens "2-g”, "2-m"e "2-j” foram encontrados em quatro estratégias; os itens "2-a", "2-i", "2-o" e "2-p" foram encontrados em três estratégias; e os itens "2-c", "2-d" e "2-n", apenas em duas estratégias. Sobre os itens "2-o" e "2-p", ambos que tratam sobre formas de avaliação, Campo e Nigro (1999) ressaltam que este processo (avaliativo) deveria ser a peça fundamental, o "motor" do processo de ensino e aprendizagem, em que professor e aluno deveriam verificar e analisar, de forma constante, o caminhar da construção dos conceitos, para que os métodos de ensino (estratégias) possam ser adaptados, se necessário.

A estratégia "pedagogia de projetos" foi a única que apresentou todos os elementos constituintes deste critério (16:16), dando continuidade às estratégias analisadas, 
a que mais apresentou elementos constituintes do critério - 2. Conteúdo - foi o ensino por investigação (13:16), seguido por educar pela pesquisa (11:16), resolução de problemas (10:16), experimentação investigativa (7:16) e situações de estudo (4:16).

Com o processo investigativo, desenvolvendo os passos da análise, foi possível depreender que o critério atitudes e valores não se aplicou de modo plenamente satisfatório como parâmetro de análise do potencial das estratégias de ensino de ciências brasileiras para a promoção de PC. Isso visto que, analisando os referencias escolhidos para a caracterização das estratégias de ensino, percebeu-se que os conteúdos atitudinais não se fazem presentes de forma significativa nas descrições das estratégias analisadas. Fato este que nos leva a acreditar que não são utilizados como parâmetro de organização de metodologia de ensino. Os conteúdos atitudinais não se referem somente a comportamentos, “[...] referem-se também a sentimentos ou valores que os alunos atribuem a determinados fatos, normas, regras, comportamentos ou atitudes" (CAMPOS; NIGRO, 1999, p. 50); e a promoção e/ou o estímulo destes sentimentos e valores característicos dos conteúdos atitudinais não ficaram explícitos nos referenciais analisados. Todavia, assim como Merchán (2011), acredita-se que determinadas atitudes e valores estimulam o desenvolvimento do PC e proporcionam a resolução de problemas e a tomada de decisão de forma responsável. A estratégia "pedagogia de projetos" foi a que se destacou, apresentando novamente todos os elementos (12:12), seguida por "ensino por investigação", numa proporção de 11:12 dos elementos de descrição.

O item Normas e critérios (item 4 da análise), trouxe muitos elementos presentes em quatro das estratégias analisadas: experimentação investigativa (6:6), ensino por investigação (5:6), pedagogia de projetos (5:6) e educar pela pesquisa (4:6). Porém, a partir da análise desse critério, compreende-se que pode não ser pertinente para perceber a presença da promoção do PC nas estratégias em contexto brasileiro, visto que os elementos constituintes deste item se constituem como um espelhamento muito direto do método científico, e isso pode estar estimulando a ideia do tecnicismo ou da racionalidade técnica, o que tende a reforçar a memorização/reprodução e não o desenvolvimento do pensamento, de acordo com Rosa e Schnetzler (2003) e Carr e Kemmis (1988). Sendo assim, as estratégias de ensino em contexto brasileiro tendem a não fazer o uso destes elementos em seu corpus teórico-metodológico, em nome da crítica à racionalidade técnica e/ou instrumental, advinda da ciência positivista. 
Ao todo, foram analisados 4 critérios, com 39 elementos constituintes do processo de promoção do PC em ciências. Na comparação entre as estratégias de ensino em contexto brasileiro, a que mais apresentou estes elementos foi a pedagogia de projetos, apresentando 38 elementos, seguida por: ensino por investigação, com 34 elementos; educar pela pesquisa, com 29 elementos; experimentação investigativa, com 26 elementos; resolução de problemas, com 19 elementos; e situações de estudo, com 10 elementos. Ressalta-se que o objetivo não é apontar uma estratégia ideal, contudo, deseja-se iniciar e divulgar uma análise da promoção do PC nestas estratégias, a partir de verificações com referenciais específicos, de origem portuguesa, o que interessa analisar com maior profundidade e em comparação com outros trabalhos. Cabe, todavia, ao professor, tornar-se ativo e crítico para adaptá-las e utilizá-las conforme o objetivo a ser atingido nas aulas de ciências, para que, assim, possa oportunizar, concomitantemente, tanto a construção de conhecimentos como o desenvolvimento do $\mathrm{PC}$, a par da promoção de uma melhor compreensão sobre as ciências, possibilitando uma alfabetização científica (TENREIRO-VIEIRA; VIEIRA, 2001).

Foi possível, também, perceber, por meio da revisão da literatura da área, que as estratégias "educar pela pesquisa" e "situações de estudo" são, dentre as cinco analisadas, as que têm sido utilizadas tanto como estratégia de formação de professores quanto como estratégias de ensino de ciências. Por exemplo, Galiazzi e Moraes (2002) defendem que a qualidade da formação inicial de professores pode ser melhorada com a integração da pesquisa no processo de formação de professor; e Boff, Araújo e Del (2009) discutem a formação inicial e continuada de professores a partir da articulação de situações de estudo. Estudos como este podem e devem ser utilizados para ajudar "[...] professores e futuros professores de ciências e de matemática a desenvolver visões mais amplas acerca da literacia científica, literacia matemática e pensamento crítico" (TENREIRO-VIEIRA; VIEIRA, 2013a, p. 166, grifo nosso). Reitera-se que não se pretende apontar estratégias de ensino ideais e/ou prontas, mas, sim, fomentar a reflexão acerca da seleção destas, para que o professor possa atingir os objetivos desejados e estimular a promoção do PC no ensino de ciências. Também cabe salientar que este estudo pode alavancar outras iniciativas brasileiras para melhor discutir e compreender esta perspectiva de ensino para as ciências. 


\section{Considerações finais}

Os critérios utilizados nesta análise são de origem portuguesa, por isso, há a necessidade de serem realizadas adaptações, com o intuito de melhor analisar a promoção do PC em ciências em contexto brasileiro. Salienta-se, também, que, a partir desse processo investigativo, surgiram outros elementos constituintes dos critérios analisados que poderão ser abordados em discussões futuras, pois, como já anunciado, trata-se de um primeiro ensaio, são eles: 1 - Conteúdo: a) discussão de conhecimentos prévios; b) comunicação dos resultados; c) levar em consideração aspectos históricos e sociais com os quais os sujeitos estão envolvidos; 2 - Capacidades de pensamento: a) argumentar; b) diferentes formas de sistematização; c) apropriação de linguagem científica; 3 - Atitudes e valores: a) desenvolver capacidade reflexiva; b) cooperação; c) tomar decisões; d) autoavaliação; 4 - Normas e critérios: a) flexibilidade para adaptação.

É importante, também, manifestar que a investigação-ação, como matriz teórica e metodológica de formação de professores, vem sendo amplamente utilizada na área de ciências com tais funções, porém são pouco percebidas inserções como estratégias de ensino, no que, acredita-se, futuramente, pode-se vir a desenvolver novas possibilidades de responder aos descompassos entre documentos curriculares, matrizes/propostas formativas das licenciaturas da área, estratégias de ensino e materiais didáticos.

A partir desta análise, identifica-se que a hipótese inicial se confirma, uma vez que todas as estratégias, tendo por base os referenciais adotados, estimulam elementos constituintes da promoção do PC de forma implícita, ou seja, apresentam elementos que podem promover o desenvolvimento do PC, porém, muitas vezes, não levam em consideração este referencial para formular suas metodologias.

Dessa forma, as estratégias possuem grande potencial para, se refletidas e reformuladas de forma crítica, além de atingir os objetivos de mediação de conceitos e conteúdos, também, promover o PC. Acredita-se que, no que se refere às formações inicial e continuada, as estratégias de ensino precisam ser (re)pensadas dentro dos elementos constituintes, para que possam ser aproveitadas em ambos os flancos, ou seja, tanto na formação inicial e/ou na continuada de professores quanto como estratégia de ensino para promoção do PC em ciências. Este é um caminho/campo que, em termos brasileiros, parece ainda carente de análise e de proposições, pois, 
em geral, as propostas curriculares nacionais, as propostas de formação de professores e as propostas de ensino (estratégias/metodologias) parecem sofrer grande descompasso em contexto brasileiro.

\section{Strategies of science teaching and a promotion of critical thinking in Brazilian context}

\section{Abstract}

Internationally studies based on a teaching and learning process based on the promotion of Critical Thinking (CP) have been increasingly valued. However, not in the Brazilian context. We believe that analyzing teaching strategies used in Brazil to teach science is crucial in order to create subsidies to facilitate understanding about the possibilities of promoting the CP, as well as its unfolding in curriculum development and teacher training processes. We analyze the Brazilian references that discuss the promotion of $\mathrm{CP}$, which showed us the precariousness of discussion about the promotion of $\mathrm{CP}$ in educational contexts. For a more detailed understanding we proceeded to analyze the following strategies: Investigative Experimentation, Research Teaching, Research Education, Problem Solving, Study Situations and Project Pedagogy. We aim to instigate new studies that will favor teachers when choosing / adapting the teaching strategy to their reality, and stimulate a more reflective process of choice directed towards the development of critical attitudes. We believe that studies in this direction can be undertaken to analyze curricular public educational policies, teaching materials and teacher training processes, in order to make efforts to progress in the development of this area, in a Brazilian context.

Keywords: Education. Science teaching. Curriculum development. Didactics. Teacher training.

\section{Notas}

1 Disponível em: http://www.scielo.org/php/index.php. Acesso em: 15 ago. 2019.

2 Disponível em: http://bancodeteses.capes.gov.br/banco-teses/\#!/. Acesso em: 15 ago. 2019.

3 Disponível em: http://www.ibict.br/. Acesso em: 15 ago. 2019.

\section{Referências}

BEYER, B. K. Improving thinking skills - defining the problem. Phi Delta Kappan, Boston, v. 1, n. 1, p. 486-490, 1984. Disponível em: http://www.jstor.org/stable/20387092?seq=1\#page_scan_ tab_contents. Acesso em: 10 abr. 2018.

BOFF, E.; ARAÚJO, M.; DEL, J. Situação de estudo: uma estratégia de formação docente no mundo em transformação. In: CONGRESO INTERNACIONAL SOBRE INVESTIGACIÓN EN DIDÁCTICA DE LÃS CIENCAS, 8. Enseñanza de lãs Ciencias, Número Extra. Anais... Barcelona: 2009. p. 1848-1851. 
BONELLI, S. M. S. O ensino de ciências nos anos iniciais do ensino fundamental: ressignificando a formação de professores. Tese (Doutorado em Educação) - Faculdade de Educação, Universidade Federal do Rio Grande do Sul, Porto Alegre, 2014.

BORDENAVE, J. D.; PEREIRA, A. M. Estratégias de ensino-aprendizagem. Petrópolis: Vozes, 2002.

BULEGON, A. M.; TAROUCO, L. M. R. Contribuições dos objetos de aprendizagem para ensejar o desenvolvimento do pensamento crítico nos estudantes nas aulas de Física. Ciência \& Educação, Bauru, v. 21, n. 3, p. 743-763, 2015.

CAMPOS, M. C. C.; NIGRO, R. G. Didática das ciências: o ensino-aprendizagem como investigação. São Paulo: FTD, 1999.

CARR, W.; KEMMIS, S. Teoría Crítica de la Ensenanza - La Investigación/Acción en la formación del professorado. Barcelona: Marinez Roca S. A., 1988.

CHANCE, P. Thinking in the classroom: a survey of programs. Nova York: Teachers College Press, 1986.

CLARKE, J. H.; BIDDLE, A. W. (ed.). Teaching critical thinking: reports from across the curriculum (Prentice Hall Studies in Writing and Culture). Englewood Cliffs, NJ: Prentice Hall, 1993.

COSTA, A. L. Developing minds: a resource book for teaching thinking. Washington, DC: Association for Supervision and Curriculum Development, 1985.

ENNIS, R. H. A logical basis for measuring critical thinking skills. Education Leadership, Alexandria, v. 43, n. 2, p. 44-48, 1985.

GALIAZZI, M.; MORAES, R. Educação pela pesquisa como modo, tempo e espaço de qualificação da formação de professores de Ciências. Ciência e Educação, Bauru, v. 8, n. 2, p. 237-252, 2002.

GONÇALVES, E.; VIEIRA, R. M. Aprender ciências e desenvolver o pensamento crítico: percursos educativos no $1^{\circ}$ ciclo do ensino básico. Indagatio Didactica, Aveiro, v. 7, n. 1, p. 7-24, jul. 2015.

GOODLAD, J. A place called school: prospects for the future. New York: McGraw-Hill, 1983.

LÜDKE, M.; ANDRÉ, M. E. D. A. Pesquisa em educação: abordagens qualitativas. São Paulo: EPU, 2011.

MALDANER, O. A.; ZANON, L. B. Situações de Estudo: uma organização do ensino que extrapola a formação disciplinar em Ciências. In: MORAES, R.; MANCUSO, R. Educação em ciências: produção de currículos e formação de professores. Ijuí: Editora Ijuí, 2004. p. 43-64.

MERCHÁN, N. Y. T. Influencia de las disposiciones en el desarrollo del pensamiento crítico y el aprendizaje de las Ciencias Naturales. Educar em Revista, Curitiba, n. 41, p. 247-259, jul. 2011.

MORAES, R.; GALIAZZI, M. C.; RAMOS, M. G. Pesquisa em sala de aula: fundamentos e pressupostos. In: MORAES, R.; LIMA, V. M. R. (org.). Pesquisa em sala de aula: tendências para a educação em novos tempos. 2. ed. Porto Alegre: EDIPUCRS, 2004. p. 9-24.

MOTTA, C. S.; DORNELES, A. M.; HECKLER, V.; GALIAZZI, M. C. Experimentação investigativa: indagação dialógica do objeto aperfeiçoável. In: ENCONTRO NACIONAL DE PESQUISA EM EDUCAÇÃO EM CIÊNCIAS, 9. Atas... Águas de Lindóia, SP: UFRJ, 2013. p. 1-8.

MEDEIROS, Maria de Fátima Gomes. O ensino da história e o pensamento reflexivo-crítico da professora no $3^{\circ}$ ano do Ensino Fundamental. 2008. 214 f. Dissertação (Mestrado em Educação) - Universidade Federal do Rio Grande do Norte, Natal, 2008. 
NININ, M. O. G. Pesquisa na escola: que espaço é esse? O do conteúdo ou o do pensamento crítico? Educação em Revista, Belo Horizonte, n. 48, p. 17-35, dez. 2008.

NOGUEIRA, N. R. Pedagogia dos projetos: uma jornada interdisciplinar rumo ao desenvolvimento das múltiplas inteligências. São Paulo: Érica, 2003.

ROSA, M. I.; SCHNETZLER, R. P. A investigação-ação na formação continuada de professores de Ciências. Ciência e Educação, Bauru, v. 9, n. 1, p. 27-39, 2003.

ROZENFELD, C. C. F.; Fóruns online na formação crítico-reflexiva de professores de línguas estrangeiras: uma representação do pensamento crítico em fases na/pela linguagem. Alfa, São Paulo, v. 58, n. 1, p. 35-62, 2014.

TENREIRO-VIEIRA, C. O pensamento crítico na educação científica. Lisboa: Instituto Piaget, 2000 .

TENREIRO-VIEIRA, C.; VIEIRA, R. M. Construindo práticas didático-pedagógicas promotoras da literacia científica e do pensamento crítico. Documentos de trabajo de Iberciencia, n. 2. Madrid: Iberciencia, 2014.

TENREIRO-VIEIRA, C.; VIEIRA, R. M. Estratégias de ensino e aprendizagem e a promoção de capacidades de pensamento crítico. In: CONGRESO INTERNACIONAL SOBRE INVESTIGACIÓN EN DIDÁCTICA DE LAS CIENCIAS, 9. Anais... Girona: Universidade de Girona, 2013a. p. 3685-3690.

TENREIRO-VIEIRA, C.; VIEIRA, R. M. Literacia e pensamento crítico: um referencial para a educação em ciências e em matemática. Revista Brasileira de Educação, Rio de Janeiro, v. 18, n. 52 , p. $163-242$, jan./mar. 2013b.

TENREIRO-VIEIRA, C.; VIEIRA, R. M. Promover o pensamento crítico dos alunos - propostas concretas para a sala de aula. Porto: Porto Editora, 2001.

VIEIRA, R. M.; TENREIRO-VIEIRA, C. Estratégias de ensino / aprendizagem: o questionamento promotor do pensamento crítico. Lisboa: Editorial do Instituto Piaget, 2005.

VIEIRA, R. O uso das TIC na promoção do pensamento crítico de futuros professores. Indagatio Didactica, Aveiro, v. 6, n. 1, p. 363-378, fev. 2014. 